\title{
To redo, or not redo, that is the question: The hazard from redo mitral valve replacement in patients considering transmitral valve-in-valve procedures
}

\author{
John Bozinovski, MD, MSc
}

\author{
From the Division of Cardiac Surgery, University of British Columbia and the Royal Jubilee Hospital, Victoria, \\ British Columbia, Canada. \\ Disclosures: Author has nothing to disclose with regard to commercial support. \\ Received for publication March 31, 2018; accepted for publication April 5, 2018; available ahead of print May 2, \\ 2018. \\ Address for reprints: John Bozinovski, MD, MSc, 106-2020 Richmond Rd, Victoria, British Columbia V8R-6R5, \\ Canada (E-mail: john.bozinovski@ubc.ca). \\ J Thorac Cardiovasc Surg 2018;156:628-9 \\ $0022-5223 / \$ 36.00$ \\ Copyright (c) 2018 by The American Association for Thoracic Surgery \\ https://doi.org/10.1016/j.jtcvs.2018.04.010
}

In this issue of the Journal, Ejiofor and colleagues ${ }^{1}$ in Boston have produced a timely and interesting analysis of the mortality that might be expected in patients who could be considered for percutaneous transmitral valve-in-valve or valve-in-ring (TMVIV/R) procedures but actually undergo reoperative mitral valve replacement (re-MVR). There are contemporary studies examining the risk of re-MVR, and the thoughtful clinician interprets and incorporates these findings when triaging care toward the values and preferences of their own patients. ${ }^{2-4}$ The utility of that practice, however, is limited by how well the population studied reflects the person before us. And herein lie both the value and limitation of the study by Ejiofor and colleagues. ${ }^{1}$

The study of Ejiofor and colleagues ${ }^{1}$ examined consecutive patients undergoing re-MVR who did not have a mechanical prosthesis, endocarditis, or the need for other valve, aortic, or coronary procedures. They contend that these patients are currently considered reasonable candidates for TMVIV/R as an alternative to re-MVR. In this "benchmark cohort," mortality was $4.1 \%$, substantially lower than the $7.1 \%$ mortality of the entire re-MVR group. This result reinforces that endocarditis and concomitant procedures add considerable risk to re-MVR.

The study suggests that the number of patients who could be considered for TMVIV/R is not large: 147 patients in 24 years (about 6 patients/year) from a large-volume center. It also suggests that re-MVR has been a reasonably safe procedure. With added comorbidities, however, a higher risk profile induces one to consider other alternatives that were not available during most of the study period. Even excluding concomitant procedures, the patients with higher risk had a significant observed mortality. Of the patients who had their Society of Thoracic Surgeons predictors of mortality score calculated, those with a Society of Thoracic Surgeons predictors of mortality score greater than $4 \%$ had an observed mortality of $8.3 \%$ (3 of 36 patients). As

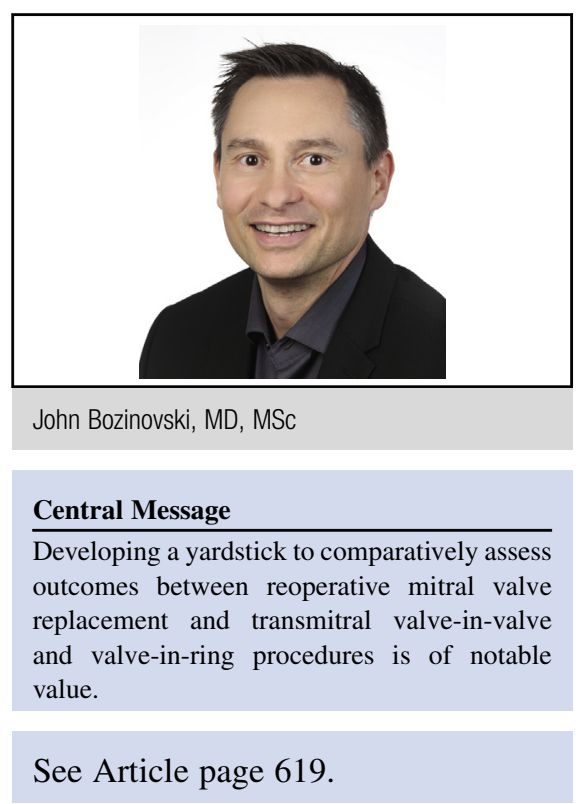

opposed to the low-risk patients, these are the patients who are arguably more reasonable potential candidates for TMVIV/R. The low numbers of patients and events in this subgroup, however, preclude drawing meaningful conclusions.

TMVIV/R carries significant risk, ${ }^{5}$ in part as a consequence of the limits of the devices, the lesser experience that we have with placing these devices, and the advanced risks of patients for whom these procedures are currently reserved. Undoubtedly, all 3 of these factors will change, and the procedure will become safer and be offered to lower-risk patients. This study had a greater number, albeit few in absolute, of these lower risk patients (42 had a calculated Society of Thoracic Surgeons predictors of mortality score lower than $4 \%$ ), and in this group only 1 operative death occurred $(2.4 \%)$. That is an admirable result for reMVR, and, if it holds true in the larger population of low-risk patients undergoing re-MVR, it provides a slim opening for TMVIV/R to displace re-MVR in this cohort.

With heart team approaches, however, we have been moving away from a context of displacement of one modality for another toward a model in which various options are available to patients. Better knowledge regarding the outcome of these options and the granularity to identify precisely subgroups within the population likely to benefit 
from a particular treatment allow greater confidence that a patient will be more accurately treated according to his or her own values and preferences.

\section{References}

1. Ejiofor JI, Hirji SA, Ramirez-Del Val F, Norman AV, McGurk S, Aranki SF, et al. Outcomes of repeat mitral valve replacement in patients with prior mitral surgery: a benchmark for transcatheter approaches. J Thorac Cardiovasc Surg. 2018;156: 619-27.

2. Mehaffey HJ, Hawkins RB, Schubert S, Fonner C, Yarboro LT, Quader M, et al. Contemporary outcomes in reoperative mitral valve surgery. Heart. 2018;104:652-6.
3. Onorati F, Perrotti A, Reichart D, Mariscalco G, Della Ratta E, Santarpino G, et al Surgical factors and complications affecting hospital outcome in redo mitral surgery: insights from a multicentre experience. Eur J Cardiothoac Surg. 2016;49: e127-33.

4. Vohra HA, Whistance RN, Roubelakis A, Burton A, Barlow CW, Tsang GM, et al. Outcome after redo-mitral valve replacement in adult patients: A 10year single-centre experience. Interact Cardiovasc Thorac Surg. 2012;14: 575-9.

5. Yoon SH, Whisenant BK, Bleiziffer S, Delgado V, Schofer $N$, Escenbach L, et al. Transcatheter mitral valve replacement for degenerated bioprosthetic valves and failed annuloplasty rings. J Am Coll Cardiol. 2017;70:1121-31 